J. Lake Sci. (湖泊科学), $2011, \mathbf{2 3}(1): 21-28$

http: //www. jlakes. org. E-mail : jlakes@niglas.ac.cn

(c) 2011 by Journal of Lake Sciences

\title{
长江中下游浅水湖泊沉积物腐殖质组分赋存特征"
}

\author{
易文利 ${ }^{1,2}$,王圣瑞 ${ }^{2 * *}$,杨苏文 ${ }^{2}$, 赵海超 $^{2}$, 金相灿 ${ }^{2}$,王国栋 ${ }^{3}$ \\ $(1$ : 宝鸡文理学院灾害监测与机理模拟陕西省重点实验室,宝鸡 721013) \\ (2: 中国环境科学研究院湖泊生态环境创新基地, 国家环境保护湖泊污染控制重点实验室, 北京 100012) \\ (3: 西北农林科技大学理学院,杨凌 712100)
}

摘 要: 应用化学方法, 对长江中下游浅水湖泊表层沉积物有机质含量、腐殖质组成及结合形态进行了研究. 结果表明: (1) 长江中下游浅水湖泊 11 个沉积物的有机质含量变化较大,在 $0.98 \%-11.0 \%$ 之间波动. 污染程度重的沉积物中有机质 含量均较污染程度轻的高, 其有机质的分布特征与沉积物污染程度和湖泊周边的人类活动有关. (2) 腐殖质组成中, 胡敏 酸 $(\mathrm{HA})$ 含量为 $1.03-6.73 \mathrm{~g} / \mathrm{kg}$, 富里酸 $(\mathrm{FA})$ 含量介于 $2.73-9.77 \mathrm{~g} / \mathrm{kg}$ 之间, 胡敏素 $(\mathrm{HM})$ 是主体, 含量在 $5.89-55.57 \mathrm{~g} / \mathrm{kg}$ 之间; $\mathrm{HA} /(\mathrm{FA}+\mathrm{HA})$ 比值 $(\mathrm{PQ})$ 处于 $23.04 \%-50.56 \%$ 之间, 平均为 $32.72 \%$. 污染程度重的沉积物 $\mathrm{PQ}$ 值大于污染程度轻 的沉积物, 说明重污染湖泊沉积物腐殖化程度高. (3) 腐殖质三种结合形态中紧结合态含量最高, 在 $3.21-47.76 \mathrm{~g} / \mathrm{kg}$ 之间; 其次为松结合态腐殖质,含量在 $0.86-6.92 \mathrm{~g} / \mathrm{kg}$ 之间; 稳结合态腐殖质最低,含量在 $0.72-3.89 \mathrm{~g} / \mathrm{kg}$ 之间; 松 $/$ 紧比与沉 积物有机质、总磷和总氮呈显著的负相关, 表明污染越严重的湖泊沉积物, 沉积物腐殖化程度高, 腐殖质积累. 因此应重 视湖泊沉积物腐殖质组分在碳循环及富营养化中的作用.

关键词: 湖泊沉积物; 有机质含量; $\mathrm{PQ}$; 腐殖质结合形态; 长江中下游

\section{Humus distribution and forms in the sediments from shallow lakes in the middle and lower reaches of the Yangtze River}

YI Wenli ${ }^{1,2}$,WANG Shengrui ${ }^{2}$, YANG Suwen ${ }^{2}$, ZHAO Haichao ${ }^{2}$, JIN Xiangcan ${ }^{2}$ \& WANG Guodong ${ }^{3}$

( $1:$ Key Lab of Disaster Monitoring and Mechanism Simulating in Shanxi Province, Baoji University of Arts and Sciences, Baoji 721013 ,P. R. China)

(2: State Environment Protection Key Laboratory for Lake Pollution Control, Research Center of Lake Eco-environment, Chinese Research Academy of Environmental Science, Beijing 100012,P. R. China)

(3: College of Science, Northwest A\& F University, Yangling 712100, P. R. China)

Abstract: The organic matter( $\mathrm{OM})$ content, compositions and fractions of shallow lake sediments were studied by chemical method from in the middle and lower reaches of Yangtze River. The results showed that the OM content varied greatly from $0.98 \%$ to $11.0 \%$, higher in the heavily polluted sediments than those in the light polluted ones. The distributions of OM content were closely related to lake pollution levels and human activity intensity. HA content was $1.03-6.73 \mathrm{~g} / \mathrm{kg}$, and FA content is higher than the HA, from 2.73 to $9.77 \mathrm{~g} / \mathrm{kg}$. Humin was the main fractions of humus, varing from 5.89 to $55.57 \mathrm{~g} / \mathrm{kg}$. $\mathrm{PQ}(\mathrm{HA} /(\mathrm{FA}+$ HA) ) ratio varied from $23.04 \%$ to $50.56 \%$, and the mean content of PQ was $32.72 \%$. PQ content were higher in the heavily polluted sediments than those in the light polluted ones, which indicated that there was a higher degree of humification in heavy polluted sediments. Combination of three kinds of humus content in the form of tightly bound humus content was the highest, and content was $3.21-47.76 \mathrm{~g} / \mathrm{kg}$; followed by loosely combined humus content between $0.86-6.92 \mathrm{~g} / \mathrm{kg}$. The stable combined hu-

* 国家自然科学基金项目 (40873079 和 40703017)、科技部国家科技基础性工作专项 “中国湖泊水质、水量和生物资 源调查” 项目 (2006FY110600)、中央级公益性科研院所基本科研业务专项项目(2007KYYW27) 和宝鸡文理学院重 点项目 (ZK0845) 联合资助. 2010-01-05 收稿;2010-03-26 收修改稿. 易文利, 女, 1975 年生, 博士, 讲师; E-mail:yw17585@163.com.

** 通讯作者;E-mail: shengruiwang@ sohu. com. 
mus were the lowest, the content varied from 0.72 to $3.89 \mathrm{~g} / \mathrm{kg}$. The loose/tight ration in the sediments were also negatively correlated with $\mathrm{OM}$, TP and TN, which showed that heavily polluted shallow lakes had higher humification and humus accumulation. So humus should be paid more attention to the carbon cycling and eutrophication control in lakes.

Keywords: Lake sediment; organic matter; PQ; combination of humus ; middle and lower reaches of Yangtze River

沉积物既能成为水体污染物的汇, 又可能是水体污染物的源, 其中沉积物有机质对沉积物一水界面污染 物的迁移转化具有重要的影响 ${ }^{[1]}$. 腐殖物质作为土壤有机质的主体, 本身含有植物所需的各种常量元素和 微量元素以及一些简单的有机化合物, 成为矿质营养和有机营养的重要来源, 同时又是土壤中某些微生物 的能量来源, 是全球碳平衡过程中非常重要的碳库 ${ }^{[2-3]}$. 因此有关腐殖质的研究一直备受各国学者的重 视 $^{[4-8]}$. 目前, 国内有关森林、农田、草原和湿地土壤腐殖质含量及其组成特征的研究较多 ${ }^{[9-12]}$. 而关于湖泊 沉积物, 因湖泊水域面积比例小,长期以来在这方面研究较少. 但是湖泊沉积物中有机质的 $70 \%$ 以上都是腐 殖质 ${ }^{[1]}$, 它可以是内源的 (来自水生生物), 也可以是外源的 (来自流域径流), 在湖泊碳循环和养分循环中 起着重要的作用 ${ }^{[13-14]}$. 为此, 本文以长江中下游浅水湖泊表层沉积物为对象, 研究长江中下游地区不同污染 程度湖泊沉积物有机质含量、腐殖质及其组分的含量及其相互关系, 以期揭示腐殖质在湖泊沉积物碳循环 中的作用及其对湖泊富营养化的影响.

\section{1 材料与方法}

\section{1 研究区概况}

本研究涉及 6 个湖泊. 其中鄱阳湖 $\left(28^{\circ} 24^{\prime}-29^{\circ} 46^{\prime} \mathrm{N}, 115^{\circ} 49^{\prime}-116^{\circ} 46^{\prime} \mathrm{E}\right)$ 是中国最大的淡水湖, 湖泊面 积 $2933 \mathrm{~km}^{2}$, 平均水深 $5.1 \mathrm{~m}$, 水位变幅巨大, 属吞吐性湖泊, 其水质在五大淡水湖中较好 ${ }^{[15]}, 2007$ 年水质 总体为 IV 类, 处于中营养状态. 洞庭湖 $\left(28^{\circ} 44^{\prime}-29^{\circ} 35^{\prime} \mathrm{N}, 111^{\circ} 53^{\prime}-113^{\circ} 05^{\prime} \mathrm{E}\right)$ 是我国第二大淡水湖, 是长江 中游一个重要集水蓄洪湖泊, 湖泊面积 $2432.5 \mathrm{~km}^{2}$, 平均水深 $6.39 \mathrm{~m}$, 全湖水质较好, 污染程度与鄱阳湖相 似, 但存在潜在变劣趋势 ${ }^{[16]}$. 洪泽湖 $\left(33^{\circ} 06^{\prime}-33^{\circ} 40^{\prime} \mathrm{N}, 118^{\circ} 10^{\prime}-118^{\circ} 52^{\prime} \mathrm{E}\right)$ 位于江苏省西北部, 是我国第四 大淡水湖. 水域面积 $1576.9 \mathrm{~km}^{2}$, 最大水深 $4.37 \mathrm{~m}$. 湖区属北亚热带季风气候, 是典型的受人工控制的大型过 水性浅水湖泊,也是 “南水北调” 东线工程重要的调蓄水库, 水体处于中营养状态 ${ }^{[17]}$. 太湖 $\left(30^{\circ} 56^{\prime}-31^{\circ} 34^{\prime} \mathrm{N}\right.$, $\left.119^{\circ} 54^{\prime}-120^{\circ} 36^{\prime} \mathrm{E}\right)$ 是我国的第三大淡水湖, 是当地重要的农业用水、饮用水、渔业用水和工业用水水源 ${ }^{[18]}$, 同时也是重要的旅游景区. 近年来, 水污染日益严重, 不同湖区呈现出不同的营养水平, 总体上已经处于富 营养化状态,威胁到源水供应和旅游景观.

月湖 $\left(30^{\circ} 33^{\prime} \mathrm{N}, 114^{\circ} 15^{\prime} \mathrm{E}\right)$ 位于武汉市中心地带, 东连龟山、北依汉水, 南靠梅子山. 目前月湖水面 $0.66 \mathrm{~km}^{2}$, 湖中淤泥厚达 $1.5 \mathrm{~m}$, 水深 $1.2 \mathrm{~m}$, 其现行功能为人体非直接接触的娱乐用水区. 玄武湖 $\left(32^{\circ} 04^{\prime} \mathrm{N}\right.$, $118^{\circ} 47^{\prime} \mathrm{E}$ ) 位于南京老城区东北部, 属典型的城市浅水型湖泊. 湖岸呈菱形, 周长约 $10 \mathrm{~km}$, 南北长 $2.4 \mathrm{~km}$, 东 西宽 $2 \mathrm{~km}$, 湖面面积 $3.7 \mathrm{~km}^{2}$, 常年水位在 $9.8-10.2 \mathrm{~m}$ 之间, 平均深度 $1.14 \mathrm{~m}$, 最大深度 $2 \mathrm{~m}$, 汇水面积 $32.78 \mathrm{~km}^{2}$. 这两大城市湖泊目前水质状况属于重富营养化状态 ${ }^{[17]}$.

\section{2 样品采集与分析}

2003 年 9 月至 2004 年 4 月在太湖、鄱阳湖、洞庭湖、洪泽湖、武汉月湖和玄武湖共设 11 个采样点(各采 样点概况见表 1 ), 现场利用柱状采样器采集表层 $10 \mathrm{~cm}$ 的沉积物样品, 混合均匀后置于封口塑料袋中, 在冰 盒中存放, 带回实验室, 放人 FD-1 冷冻干燥机中真空干燥后研磨、过篮, 保存在磨口玻璃瓶中备用.

沉积物样品经浓 $\mathrm{H}_{2} \mathrm{SO}_{4}-\mathrm{CuSO}_{4}$ - $\mathrm{Se}$ 催化消煮后, 用 KDY-9820 型凯氏定氮仪测定总氮含量 ${ }^{[19]}$; SMT 法测 定总磷含量 ${ }^{[20]}$; 经典的重铬酸钾容量法-外加热法测定有机质总量 ${ }^{[19]}$; 腐殖质中胡敏酸 $(\mathrm{HA})$ 、富里酸 (FA) 和胡敏素 $(\mathrm{HM})$ 组分和可提取腐殖质总量 $(\mathrm{HE})$ 采用焦磷酸钠提取一重铬酸钾法测 ${ }^{\text {定 }}{ }^{[19]}$; 沉积物腐殖质结合 形态采用傅积平修改法测定 ${ }^{[21]}$, 即用氢氧化钠及氢氧化钠和焦磷酸钠混合液分别连续提取松结合态和稳结 合态腐殖质,残留态腐殖质为紧结合态腐殖质; 沉积物粒径分析采用英国 Malvern 公司产的 Matersizer 2000 型激光粒度仪, 其分析范围为 $0.02-2000 \mu \mathrm{m}$. 激光的波长是 $750 \mathrm{~nm}$, 精度 $\leqslant 1 \%$, 平均测样时间 5-7 min. 为了 保证数据准确,对每个样品做 3 个平行,数据取平均值,用 SPSS 10.0 进行统计分析. 


\section{2 结果与分析}

\section{1 沉积物特征}

根据目前国内环境保护疏浚的一般要求,沉积物总磷含量在 $500 \mathrm{mg} / \mathrm{kg}$ 以上,该沉积物就已经被认为污 染严重, 建议进行疏浚, 而 $500 \mathrm{mg} / \mathrm{kg}$ 以下, 则认为该沉积物还较清洁, 没有必要疏浚 ${ }^{[22]}$. 本研究的 11 个沉积 物样品中, 武汉的月湖和南京的玄武湖总磷含量都超过 $1000 \mathrm{mg} / \mathrm{kg}$, 属于重污染的湖泊沉积物; 太湖的五里 湖、梅梁湾、洞庭湖和洪泽湖的总磷含量也较高 $(500-1000 \mathrm{mg} / \mathrm{kg})$, 属于污染较重的湖泊沉积物; 鄱阳湖和 太湖的贡湖 $(\mathrm{TP}<500 \mathrm{mg} / \mathrm{kg}$ ) 则为轻度污染的湖泊沉积物 (表 1). 所以本研究所选 11 个沉积物样品分别代 表重度、较重和轻度污染湖泊 3 种污染类型.

表 1 沉积物采样点、颗粒组成与营养物含量

Tab. 1 Location, particle size and nutrient contents of sediments

\begin{tabular}{|c|c|c|c|c|c|c|c|}
\hline \multirow{2}{*}{ 湖泊 } & \multirow{2}{*}{ 沉积物编号 } & \multirow{2}{*}{ 样点状况 } & \multirow{2}{*}{$\begin{array}{c}\mathrm{TP} \\
(\mathrm{mg} / \mathrm{kg})\end{array}$} & \multirow{2}{*}{$\begin{array}{c}\mathrm{TN} \\
(\mathrm{mg} / \mathrm{kg})\end{array}$} & \multicolumn{3}{|c|}{ 颗粒粒度分布 (\%) } \\
\hline & & & & & 粘粒 & 粉砂粒 & 砂粒 \\
\hline \multirow[t]{2}{*}{ 武汉月湖 } & $\mathrm{Y}-1$ & 湖中 (梅子山, “七” 字围墙正前方约 $100 \mathrm{~m}$ 处) & 1640 & 5166 & 6.28 & 81.8 & 11.91 \\
\hline & $\mathrm{Y}-2$ & 湖中 (油脂化学厂排污口正前方约 $100 \mathrm{~m}$ 处) & 2051 & 5190 & 7.53 & 83.4 & 9.07 \\
\hline \multirow[t]{3}{*}{ 太湖 } & T-G & 湖中 $\left(31^{\circ} 24^{\prime} 843^{\prime \prime} \mathrm{N}, 120^{\circ} 15^{\prime} 242^{\prime \prime} \mathrm{E}\right)$ & 400.8 & 767.6 & 3.43 & 68.5 & 28.07 \\
\hline & $\mathrm{T}-\mathrm{W}$ & 湖中 $\left(31^{\circ} 31^{\prime} 23^{\prime \prime} \mathrm{N}, 120^{\circ} 16^{\prime} 35^{\prime \prime} \mathrm{E}\right)$ & 731.6 & 1884 & 7.95 & 71 & 21.05 \\
\hline & $\mathrm{T}-\mathrm{M}$ & 湖中, 水厂附近 $\left(31^{\circ} 31^{\prime} 325^{\prime \prime} \mathrm{N}, 120^{\circ} 09^{\prime} 340^{\prime \prime} \mathrm{E}\right)$ & 576 & 1023 & 4.43 & 70.31 & 25.26 \\
\hline \multirow[t]{3}{*}{ 鄱阳湖 } & B-1 & 主航道 $\left(29^{\circ} 36^{\prime} 617^{\prime \prime} \mathrm{N}, 116^{\circ} 07^{\prime} 841^{\prime \prime} \mathrm{E}\right)$ & 323.7 & 627.9 & 4.21 & 59.6 & 31.07 \\
\hline & B-2 & 主航道 $\left(29^{\circ} 37^{\prime} 505^{\prime \prime} \mathrm{N}, 116^{\circ} 08^{\prime} 739^{\prime \prime} \mathrm{E}\right)$ & 427.6 & 770 & 4.63 & 64.3 & 36.19 \\
\hline & B-3 & 主航道 $\left(29^{\circ} 37^{\prime} 72^{\prime \prime} \mathrm{N}, 116^{\circ} 08^{\prime} 419^{\prime \prime} \mathrm{E}\right)$ & 486.1 & 949 & 4.72 & 64.8 & 30.48 \\
\hline 玄武湖 & $\mathrm{X}^{*}$ & 湖中 $\left(32^{\circ} 03^{\prime} \mathrm{N}, 118^{\circ} 47^{\prime} \mathrm{E}\right)$ & 1062.4 & 3704 & 6.96 & 70.4 & 22.64 \\
\hline 洪泽湖 & $\mathrm{H}$ & 湖中 $\left(33^{\circ} 19^{\prime} 23.8^{\prime \prime} \mathrm{N}, 118^{\circ} 50^{\prime} 57.1^{\prime \prime} \mathrm{E}\right)$ & 639.9 & 1190 & 7.02 & 68.5 & 24.8 \\
\hline 洞庭湖 & $\mathrm{D}$ & 南嘴, 澧水人湖口处 $\left(29^{\circ} 03^{\prime} 48^{\prime \prime N}, 112^{\circ} 17^{\prime} 45^{\prime \prime} \mathrm{E}\right)$ & 775 & 2045 & 6.75 & 74.34 & 18.23 \\
\hline
\end{tabular}

*表示底泥已疏浚过; 粘粒 $(<0.002 \mathrm{~mm})$; 粉砂粒 $(0.002-0.05 \mathrm{~mm})$; 砂粒 $(0.05-2 \mathrm{~mm})$.

已有研究表明,不同粒径的沉积物颗粒具有不同的比表面积和重量而表现出不同特征. 较细的粘粒和 粉砂粒对污染物有较强的吸附能力和再悬浮能力, 所以粘粒和粉砂粒所占比例较高的沉积物, 污染程度一 般较高 ${ }^{[23]}$. 所选 11 种沉积物样品颗粒分布在 $0-2 \mathrm{~mm}$ 粒度区间, 其中粘粒组分 ( < $\left.0.002 \mathrm{~mm}\right)$ 占 $3.43 \%-$ $7.95 \%$, 粉砂组分 $(0.002-0.05 \mathrm{~mm})$ 占 $59.6 \%-83.4 \%$, 砂粒组分 $(0.05-2 \mathrm{~mm})$ 占 $9.07 \%-36.19 \%$ (表 1$)$. 所选沉积物的主要粒径组成以粉砂粒级为主. 该结 果与文献 ${ }^{[17,24-25]}$ 类似. 粒径分析测定的 11 个样品 中,重污染的沉积物粉砂粒级比例高于污染较轻沉 积物的粉砂粒级比例. 本研究中所选用的 11 种沉 积物有机质含量随细颗粒 $($ 粘粒 + 粉砂粒 $)$ 含量的 升高而增加 $(r=0.859, P<0.01)$ (表 1 , 图 1). 由此 可见,本研究中湖泊沉积物细颗粒越多,有机质含 量越高.

\section{2 不同污染程度沉积物有机质含量及分布}

土壤有机质是指存在于土壤中所有含碳有机 物质, 它包括土壤中各种动植物残体、微生物体及 其分解和合成的各种有机物质 ${ }^{[26]}$. 而沉积物有机质 含量是反映其营养水平的重要指标之一. 长江中下 游浅水湖泊 11 个沉积物的有机质含量为 $0.98 \%-$ $11.0 \%$, 平均值为 $3.72 \%$. 重污染的沉积物主要分

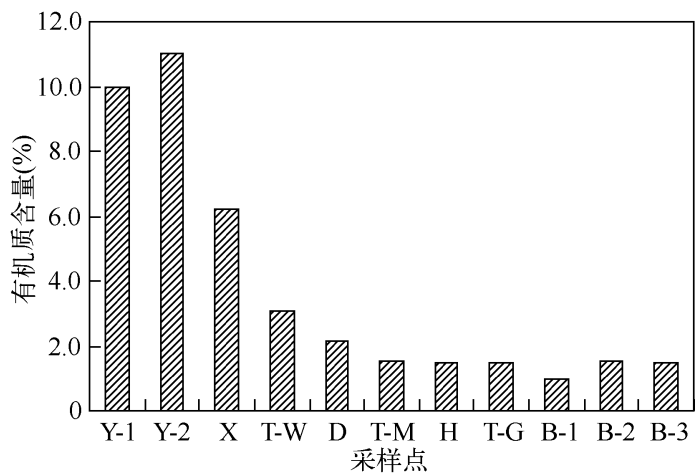

图 1 长江中下游浅水湖泊 11 个沉积物的 有机质含量

Fig. 1 Contents of organic matter of the 11 sediments from shallow lakes in the middle and lower reaches of the Yangtze River 
布在武汉月湖、南京玄武湖, 其有机质含量为 $6.23 \%-11.0 \%$, 平均值为 $9.06 \%$; 较重污染的沉积物, 该系列 沉积物主要分布在洪泽湖、洞庭湖、太湖 (五里湖和梅梁湾), 其有机质含量为 $1.50 \%-3.05 \%$, 平均值为 $2.05 \%$; 污染较轻的沉积物主要分布在太湖的贡湖、鄱阳湖, 其有机质含量为 $0.98 \%-1.55 \%$, 平均值为 $1.38 \%$. 总体而言, 本研究中重污染的湖泊沉积物有机质含量均较污染程度轻的高, 重污染的月湖、玄武湖 沉积物有机质含量的平均值是污染程度较重的五里湖、梅梁湾、洞庭湖和洪泽湖沉积物有机质含量平均值 的 4.42 倍、是污染程度较轻的鄱阳湖和贡湖有机质含量的平均值的 6.57 倍.

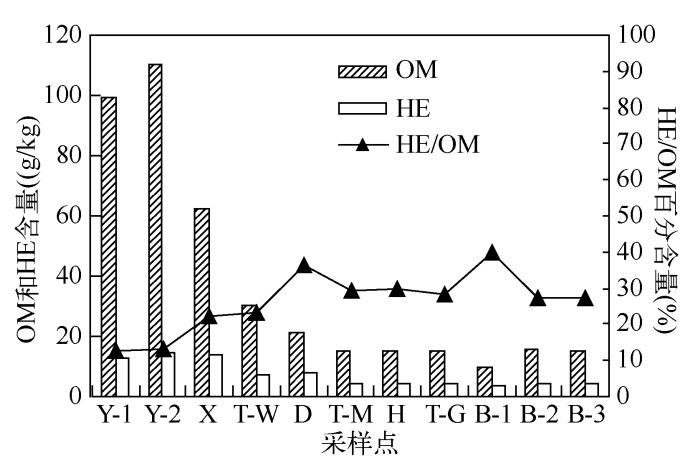

图 2 长江中下游浅水湖泊 11 个沉积物的 有机质、HE、HE/OM

Fig. 2 Contents of organic matter, HE and HE/OM of the 11 sediments from shallow lakes in the middle and lower reaches of the Yangtze River

\section{3 不同污染程度沉积物不同腐殖质组分含量及分} 布特征

腐殖质作为有机质的主体部分, 主要由富里酸 (FA, 即溶于酸又溶于碱), 胡敏酸 (HA, 只溶于碱而不 溶于酸) 和胡敏素 (HM, 酸碱都不溶) ${ }^{[27-28]}$ 组成. 前两 项合称为可提取腐殖质 (HE). HE 的相对含量即为可 提取腐殖质占沉积物总有机质的百分数. 总有机质中 可提取腐殖质的相对含量随有机质含量的增加而下降 $(r=-0.870, P<0.01)$ (图 2), 可能是由于沉积物总 有机质中可提取腐殖质的比例与沉积物粘土矿物含量 密切相关, 沉积物粘土矿物越高, 矿物与腐殖质相互作 用越强,腐殖质中可提取组分的含量就越低 ${ }^{[29]}$.

长江中下游地区湖泊胡敏酸含量 (HA) 在 $1.03-$ $6.73 \mathrm{~g} / \mathrm{kg}$ 间, 占总有机质的 $4.48 \%-12.13 \%$, 富里酸 含量普遍高于胡敏酸, 在 $2.73-9.77 \mathrm{~g} / \mathrm{kg}$ 间, 占总有 机质的 $7.04 \%-27.81 \%$ (表 2). 说明所研究的浅水湖泊沉积物中最活跃的有机酸是富里酸. 这一结果与土 壤中腐殖质组成存在差异 ${ }^{[30-31]}$. 碱性和富氧条件下有利于 FA 的形成, 而酸性和缺氧条件有利于 HA 的形 成. 本研究所选用的 11 个湖泊沉积物都是浅水湖泊且呈弱碱性条件, 容易进行大气复氧所以富里酸含量较 $\mathrm{HA}$ 高. 与土壤有机质一样, 胡敏素占主导, 含量 $5.89-95.57 \mathrm{~g} / \mathrm{kg}$.

\section{表 2 长江中下游浅水湖泊沉积物有机质及其组分分析}

Tab. 2 Composition and total content of organic matter in the sediments of various lakes

\begin{tabular}{|c|c|c|c|c|c|c|c|c|}
\hline \multirow{2}{*}{ 采样点 } & \multirow{2}{*}{$\begin{array}{c}\mathrm{HE} \\
(\mathrm{g} / \mathrm{kg})\end{array}$} & \multicolumn{6}{|c|}{ 各组分含量及其所占总有机质含量百分比 } & \multirow{2}{*}{$\begin{array}{c}P Q \\
(\%)\end{array}$} \\
\hline & & $\mathrm{HA}(\mathrm{g} / \mathrm{kg})$ & $\mathrm{HA} / \mathrm{OM}(\%)$ & $\mathrm{FA}(\mathrm{g} / \mathrm{kg})$ & $\mathrm{FA} / \mathrm{OM}(\%)$ & $\mathrm{HM}(\mathrm{g} / \mathrm{kg})$ & $\mathrm{HM} / \mathrm{OM}(\%)$ & \\
\hline Y-1 & 12.74 & 4.45 & 4.48 & 8.29 & 8.34 & 86.81 & 87.28 & 34.93 \\
\hline $\mathrm{Y}-2$ & 14.47 & 6.73 & 6.11 & 7.75 & 7.04 & 95.57 & 86.85 & 46.48 \\
\hline $\mathrm{X}$ & 13.83 & 4.06 & 6.51 & 9.77 & 15.67 & 10.81 & 71.85 & 29.36 \\
\hline $\mathrm{T}-\mathrm{W}$ & 7.10 & 3.59 & 11.77 & 3.51 & 11.50 & 23.40 & 76.73 & 50.56 \\
\hline $\mathrm{D}$ & 7.83 & 2.33 & 10.83 & 5.50 & 25.63 & 10.89 & 70.93 & 29.76 \\
\hline T-M & 4.46 & 1.28 & 8.46 & 3.18 & 20.97 & 5.89 & 60.06 & 28.70 \\
\hline $\mathrm{H}$ & 4.46 & 1.03 & 6.85 & 3.44 & 22.93 & 11.32 & 72.78 & 23.04 \\
\hline T-G & 4.24 & 1.22 & 8.13 & 3.01 & 20.02 & 10.81 & 72.23 & 28.84 \\
\hline B-1 & 3.92 & 1.19 & 12.13 & 2.73 & 27.81 & 48.49 & 77.57 & 30.36 \\
\hline B-2 & 4.23 & 1.28 & 8.25 & 2.95 & 18.98 & 10.52 & 69.90 & 30.26 \\
\hline B-3 & 4.09 & 1.13 & 7.57 & 2.97 & 19.90 & 12.72 & 61.90 & 27.56 \\
\hline
\end{tabular}

重污染的城市湖泊 (月湖、玄武湖) HA 平均含量的变化趋势分别是污染较重的湖泊 (梅梁湾、五里湖、 洞庭湖、洪泽湖) 和污染较轻的湖泊的 2.2 倍与 3 倍; FA 平均含量的变化趋势分别是污染较重的湖泊 (梅梁 湾、五里湖、洞庭湖、洪泽湖) 和污染较轻的湖泊的 2.5 倍与 4.2 倍. 这一结果说明, 随着沉积物有机质含量 的增加,胡敏酸和富里酸含量也是逐渐增加的, 验证了 HA 和 FA 的含量取决于有机质总量.

$P Q$ 为胡敏酸 $(H A)$ 占可提取腐殖质 $(H A+F A)$ 的百分比, 与 $H A / F A$ 同义, 均可作为腐殖质化程度的指 
标, 表征腐殖质组成的变化 ${ }^{[32]}$. 重污染的城市湖泊月湖和玄武湖的 PQ 值介于 $29.36 \%-46.48 \%$, 平均为 $46.71 \%$; 较重污染湖泊沉积物 $P Q$ 值介于 $23.04 \%-50.56 \%$ 之间, 平均值为 $33.01 \%$, 轻污染湖泊沉积物 $P Q$ 值介于 $27.56 \%-30.36 \%$, 平均值为 $29.25 \%$ (表 2 ). 说明重污染湖泊沉积物腐殖化程度 > 较重污染湖泊沉 积物 > 轻污染湖泊沉积物. 同时不同污染程度湖泊沉积物的 PQ 值变化较大, 表明 3 种不同污染程度的湖泊 沉积物腐殖化程度存在空间差异. 这可能与所选湖泊沉积物受污染程度不同所致.

\section{4 不同污染程度沉积物腐殖质结合形态}

腐殖质本身是结构十分复杂的高分子聚合物, 对其进行分组研究十分必要. 徐建明 ${ }^{\text {等 }}{ }^{[33]}$ 根据有机矿质 复合体中腐殖质与矿物质的结合程度分为三种形态, 松结合态腐殖质 (HE I )、稳结合态腐殖质 (HE II) 和 紧结合态腐殖质 (HE III ). 紧结合态腐殖质反映“老化” 状况, 稳结合态腐殖质反映正在进行的松结合态腐殖 质向紧结合态腐殖质转化的过程, 松结合态腐殖质是腐殖质中活性最大的部分 ${ }^{[34]}$.

重组有机碳含量为 $5.05-58.18 \mathrm{~g} / \mathrm{kg}$, 占总有机质的 $83.11 \%-97.75 \%$ (表 3), 表明沉积物中轻组有机 质基本被彻底分解,所含的有机质大部分为很难分解的重组有机质. 且 11 种不同污染程度的沉积物重组有 机碳含量变化与总有机质含量变化趋势相一致.

表 3 不同污染程度的沉积物腐殖质的结合形态 *

Tab. 3 Combination of humus in different polluted sediment

\begin{tabular}{|c|c|c|c|c|c|c|c|c|c|}
\hline \multirow[b]{2}{*}{ 采样点 } & \multirow{2}{*}{$\begin{array}{l}\text { HFOM } \\
(\mathrm{g} / \mathrm{kg})\end{array}$} & \multicolumn{2}{|c|}{ HE I } & \multicolumn{2}{|c|}{ HE II } & \multicolumn{2}{|c|}{ HE III } & \multirow{2}{*}{$\begin{array}{l}\text { HE I/ } \\
\text { HE II }\end{array}$} & \multirow{2}{*}{$\begin{array}{l}\mathrm{HE} \mathrm{I} / \\
\mathrm{HE} \text { II }\end{array}$} \\
\hline & & $\begin{array}{l}\text { 含碳量 } \\
(\mathrm{g} / \mathrm{kg})\end{array}$ & $\begin{array}{c}\text { 占 } \mathrm{HFOM} \\
\text { 百分比 }(\%)\end{array}$ & $\begin{array}{l}\text { 含碳量 } \\
(\mathrm{g} / \mathrm{kg})\end{array}$ & $\begin{array}{c}\text { 占 HFOM } \\
\text { 百分比 }(\%)\end{array}$ & $\begin{array}{l}\text { 含碳量 } \\
(\mathrm{g} / \mathrm{kg})\end{array}$ & $\begin{array}{c}\text { 占 HFOM } \\
\text { 百分比 (\%) }\end{array}$ & & \\
\hline Y-1 & 52.84 & 6.17 & 11.68 & 3.70 & 7.00 & 42.96 & 81.30 & 1.67 & 0.14 \\
\hline $\mathrm{Y}-2$ & 58.18 & 6.92 & 11.89 & 3.66 & 6.29 & 47.76 & 82.09 & 1.89 & 0.14 \\
\hline $\mathrm{X}$ & 34.28 & 5.16 & 15.05 & 3.89 & 11.35 & 24.17 & 70.51 & 1.33 & 0.21 \\
\hline $\mathrm{T}-\mathrm{W}$ & 17.17 & 2.91 & 16.95 & 1.78 & 10.37 & 11.79 & 68.67 & 1.63 & 0.25 \\
\hline $\mathrm{D}$ & 11.95 & 2.50 & 20.92 & 1.74 & 14.56 & 7.70 & 64.44 & 1.44 & 0.32 \\
\hline T-M & 7.31 & 1.37 & 18.74 & 0.97 & 13.27 & 4.80 & 65.66 & 1.41 & 0.29 \\
\hline $\mathrm{H}$ & 8.47 & 1.64 & 19.36 & 1.79 & 21.13 & 5.22 & 61.63 & 0.92 & 0.31 \\
\hline T-G & 8.35 & 1.75 & 20.96 & 0.90 & 10.78 & 5.69 & 68.14 & 1.94 & 0.31 \\
\hline B-1 & 5.05 & 1.07 & 21.19 & 0.97 & 19.21 & 3.21 & 63.56 & 1.10 & 0.33 \\
\hline B-2 & 7.60 & 1.51 & 19.87 & 1.09 & 14.34 & 5.11 & 67.24 & 1.39 & 0.30 \\
\hline B-3 & 7.25 & 1.46 & 20.14 & 0.72 & 9.93 & 5.06 & 69.79 & 2.03 & 0.29 \\
\hline
\end{tabular}

* HFOM 为重组有机碳总量 $(\mathrm{g} / \mathrm{kg}) ; \mathrm{HE} \mathrm{I}$ 为松结合态腐殖质; HE II 为稳结合态腐殖质; HE III 为紧结合态腐殖质.

不同沉积物 3 种结合形态腐殖质均有: 重污染的月湖、玄武湖 > 较重污染的太湖五里湖、洞庭湖、梅梁湾 和洪泽湖 > 轻污染的太湖贡湖和鄱阳湖 (表 3) , 并都以紧结合态腐殖质含量最高, 含量在 $3.21-47.76 \mathrm{~g} / \mathrm{kg}$; 其 次为松结合态腐殖质,含量在 $1.07-6.92 \mathrm{~g} / \mathrm{kg}$ 之间; 稳结合态腐殖质最低, 含量在 $0.72-3.89 \mathrm{~g} / \mathrm{kg}$ 之间. 松 结合态腐殖质含量与紧结合态腐殖质含量的比值, 一般可用来反映腐殖质的活性和质量 ${ }^{[35-36]}$, 比值大意味 着腐殖质活性较高, 比值小说明腐殖质活性较低 ${ }^{[37]}$. 松、稳、紧结合态腐殖质所占百分比的变化规律并不明 显,但是重污染的城市湖泊 (月湖、玄武湖) 其松/紧的平均值 <污染较重的湖泊 (太湖的五里湖和梅梁湾、洞 庭湖、洪泽湖) <污染较轻的湖泊 (贡湖和鄱阳湖), 说明污染越严重, 湖泊沉积物腐殖质趋于老化, 活性 较低.

\section{3 讨论}

\section{1 长江中下游浅水湖泊沉积物有机质含量与及分布}

从 11 个浅水湖泊沉积物所处的地理条件来看, 玄武湖位于南京老城区东北部, 月湖位于武汉市中心地 带, 二者均属典型的浅水型城市湖泊,近 20 年来, 随着湖周围工厂增加和人口增长, 大量污染物进人水体, 其沉积物的总磷、总氮含量均明显高于其它各湖泊 (表 1), 导致水体处于严重富营养化状态; 太湖、鄱阳湖、 洪泽湖、洞庭湖属于大型自然湖泊, 该系列湖泊水体处于中-富营养化状态, 污染相对较轻 ${ }^{[17]}$. 说明在本研 
究条件下, 长江中下游浅水湖泊沉积物总有机质分布与湖泊的区域特点及人类活动密切相关; 而沉积物的 有机质、CEC、总磷和总氮均可作为指示其污染程度的指标, 且总磷和总氮、有机质和 CEC 有很好的相关 性 ${ }^{[17]}$, 进一步说明了沉积物有机质含量大小随沉积物污染程度增大而增大. 所以长江中下游浅水湖泊沉积 物有机质的分布特征不仅与其污染程度有关,而且与人类活动密切相关.

\section{2 浅水湖泊沉积物腐殖质组成}

据调查, 土壤中储存的有机碳 (3 万亿吨) 中 $80 \%$ 左右是腐殖质碳, 是陆地植被碳的 4 倍多. Schnitzer 和 Ghosh 等研究发现, 假如陆地土壤中的腐殖质多分解 $10 \%$, 大气中的 $\mathrm{CO}_{2}$ 浓度将会增加 $30 \%$, 将会导致灾难 性后果, 足见土壤腐殖质对碳平衡的影响之大 ${ }^{[38]}$. 虽然湖泊水域面积占陆地面积比例较小, 但沉积物中有机 质的 70\% 以上都是腐殖质, 它们的加速分解, 也将会对全球碳循环产生很大影响. 因此湖泊沉积物中腐殖质 组成也应得到重视.

目前, 有关沉积物有机质特征的研究方法主要采用土壤有机质的研究方法. 与土壤不同, 沉积物中有机 质主要以腐殖质形态存在,一般认为沉积物中的腐殖质含量约为有机质总量的 $70 \%-80 \%$, 有的区域甚至达 到 $99 \%{ }^{[39]}$. 腐殖物质也有多种分组方法, 但比较传统和应用较广的是将腐殖物质分为胡敏酸 (HA)、富里酸 (FA) 和胡敏素 (HM). 腐殖质组分中含有多种官能团, 是对污染物的吸附一解吸过程起主要作用的组分 ${ }^{[33]}$. 因此, 腐殖质的含量与有机质含量之间有密切的关系. 经过对 11 个浅水湖泊沉积物有机质含量与腐殖质含 量的相关系数可以看出, 腐殖质中的富里酸、胡敏酸和胡敏素 3 个指标均与有机质存在显著的相关性 (分别 为 $r=0.859, P<0.01 ; r=0.941, P<0.01 ; r=0.820, P<0.01)$. 这一结果说明, 随着沉积物有机质含量的增 加, 胡敏酸和富里酸含量也是逐渐增加的, 验证了 HA 和 FA 的含量取决于有机质总量.

有机质分解转化过程包括矿化和腐殖化过程. 矿化过程是指动、植物残体及腐殖质物质, 在微生物的作 用下, 分解成简单无机化合物的过程. 腐殖化过程是指土壤、堆肥或江河海等水体淤泥中的有机质转变为腐 殖质的过程. 有机质的化学组成、土壤的水、热状况、渍水和低温环境等有利于腐殖化过程的进行, 腐殖质积 累量也较多.

腐殖质具有对气候环境变化相应敏感的特点. 较高的腐殖化度, 指示气候相对湿润, 湖泊生产力高, 湖 泊水生植物大量繁殖, 湖泊流域内生物量增大, 从而造成沉积物有机质含量增加, 腐殖质在温湿环境下积累 加强; 而较低的腐殖化度, 指示空气相对干燥, 湖泊生产力下降, 流域生物量变小, 陆源有机质输人减少, 有 机质含量降低, 不利于腐殖质积累 ${ }^{[40]} . \mathrm{PQ}$ 值可以作为腐殖化程度的指标, PQ 值高说明腐殖化程度高, 腐殖 质积累 ${ }^{[40]}$, 有机碳和其它营养盐暂时退出循环; 反之则说明腐殖化程度低, 即腐殖质被微生物分解发生矿化 作用, 有机碳及其它营养元素进人再循环. 因此, 湖泊沉积物的腐殖化程度增加会降低对碳循环的贡献. 本 研究结果表明, $\mathrm{PQ}$ (胡敏酸/ (富里酸 + 胡敏酸) ) 比值处于 $23.04 \%-50.56 \%$ 之间, 平均为 $32.72 \%$. 重污染的 城市湖泊月湖和玄武湖的 PQ 值介于 $29.36 \%-46.48 \%$, 平均为 $46.71 \%$; 较重污染湖泊沉积物 PQ 值介于 $23.04 \%-50.56 \%$ 之间, 平均值为 $33.01 \%$, 轻污染湖泊沉积物 PQ 值介于 $27.56 \%-30.36 \%$, 平均值为 $29.25 \%$. 重污染湖泊沉积物腐殖化程度 > 较重污染湖泊沉积物 > 轻污染湖泊沉积物. 重污染湖泊沉积物腐 殖质对碳循环的贡献较小.

\section{3 沉积物腐殖质结合形态的的含量与分布}

松紧比是衡量腐殖质品质的一个重要指标, 可表征腐殖质活性, 比值高说明腐殖质容易被微生物矿化 转化为无机碳和植物可利用的营养盐; 反之, 腐殖质很难被微生物分解, 导致腐殖质积累, 使腐殖化程度 增加.

本研究结果表明, 重污染的城市湖泊 (月湖、玄武湖) 其松/紧比平均值 <污染较重的湖泊 (太湖的五里 湖、梅梁湾、洞庭湖、洪泽湖) <污染较轻的湖泊 (贡湖和鄱阳湖), 说明污染越严重, 湖泊沉积物腐殖质趋于 老化, 活性较低, 腐殖质很难被微生物分解, 腐殖质积累, 腐殖化程度增高. 同时还研究了松/紧比值与有机 质、总磷和总氮的关系, 结果为显著的负相关 (分别为 $r=-0.976^{* *}, r=-0.952^{* *}, r=-0.958^{* *}$ ), 进一步 说明了污染越严重的湖泊沉积物, 沉积物腐殖化程度高, 腐殖质积累. 大量有机质的积累使沉积物更加肥 沃, 进而极大地影响植物生长, 一旦条件改变, 使得所积累的腐殖质加速分解, 将会对全球碳循环产生一定 的影响, 同时也会加剧湖泊富营养化. 因此, 应重视湖泊沉积物腐殖质组分在碳循环及富营养化中的作用. 


\section{4 结论}

(1) 长江中下游浅水湖泊 11 个沉积物的有机质含量为 $0.98 \%-11.0 \%$. 其有机质的分布特征与其污染 程度和人类活动有关. 总趋势为, 污染严重的城市湖泊沉积物有机质含量均较自然湖泊高, 而自然湖泊中, 污染较重的太湖的五里湖、梅梁湾、洞庭湖和洪泽湖有机质含量高于污染较轻的鄱阳湖和太湖的贡湖湾.

(2) 长江中下游地区湖泊胡敏酸含量为 $1.03-6.73 \mathrm{~g} / \mathrm{kg}$, 占总有机质 $4.48 \%-12.13 \%$, 富里酸含量普遍高 于胡敏酸, 在 $2.73-9.77 \mathrm{~g} / \mathrm{kg}$ 之间, 占总有机质 $7.04 \%-27.81 \%$. 胡敏素占主导, 含量 $5.89-55.57 \mathrm{~g} / \mathrm{kg}$. 重污 染的城市湖泊月湖和玄武湖的 $P Q$ 值介于 $29.36 \%-46.48 \%$, 平均为 $46.71 \%$; 较重污染湖泊沉积物 PQ 值介 于 $23.04 \%-50.56 \%$ 之间, 平均值为 $33.01 \%$, 轻污染湖泊沉积物 PQ 值介于 $27.56 \%-30.36 \%$, 平均值为 $29.25 \%$. 重污染湖泊沉积物腐殖化程度 > 较重污染湖泊沉积物 > 轻污染湖泊沉积物. 重污染湖泊沉积物腐 殖质对碳循环的贡献相对较小.

(3) 腐殖质三种结合形态含量中, 紧结合态腐殖质含量最高, 含量在 $3.21-47.76 \mathrm{~g} / \mathrm{kg}$; 其次为松结合 态腐殖质, 在 $1.07-6.92 \mathrm{~g} / \mathrm{kg}$ 之间; 稳结合态腐殖质最低, 含量在 $0.72-3.89 \mathrm{~g} / \mathrm{kg}$ 之间. 重污染的城市湖泊 (武汉月湖、玄武湖) 其松/紧比平均值 <污染较重的湖泊 (太湖的五里湖、梅梁湾、洞庭湖、洪泽湖) <污染 较轻的湖泊 (贡湖和鄱阳湖), 松/紧比值与沉积物有机质、总磷和总氮呈显著的负相关, 表明污染越严重的 湖泊沉积物, 沉积物腐殖化程度高, 腐殖质积累.

\section{5 参考文献}

[1]朱广伟,陈英旭. 沉积物中有机质的环境行为研究进展. 湖泊科学, 2001,13(3):272-279.

[2] 沈永明,杨劲松,增 华等. 互花米草盐沼湿地土壤腐殖质的空间分布特征. 农业环境科学学报, 2008,27(6): 2279-2284.

[ 3 ] Keeves. Some evidence of loss of productivity with successive rotations of Pinus radiata in the southeast of South Australia. Aust For , 1996,30:51-63.

[ 4 ] Grathwohl P. Influence of organic matter from soils and sediments from various origins on the sorption of some chlorinated aliphatic hydrocarbons: implications on Koc correlations. Environs Technol, 1990, 24(11) :1687-1693.

[ 5 ] Grisi B, Grace C, Brookes PC et al. Temperature effects on organic matter and microbial biomass dynamics in temperate and tropical soils. Soil Biology \& Biochemistry, 30(10-11),1998:1309-1315.

[6] 窦 森. 核磁共振波谱在土壤有机质研究中的应用.土壤通报,1988,19(5):237-239.

[ 7 ] Kang KH, Shin HS, Park H. Characterization of humic substances present in landfill leachates with different landfill ages and its implications. Water Research, $2002, \mathbf{3 6}: 4023-4032$.

[ 8 ] Fooken U, Libezeit G. Distinction of marine and terrestrial origin of humic acids inNorth Sea surface sediments by absorption spectroscopy. Marine Geology, 2000,164:173-181.

[9] 刘淑霞, 刘景双,赵兰坡等. 吉林省主要耕地土壤中结合态腐殖质组成特征的研究. 吉林农业大学学报, 2002,24 (1) : $72-76$.

[10］裴海坤,朱志红,乔有明等. 不同草甸植被类型下土壤腐殖质及有机磷类型探讨. 草业学报,2001,10(4):18-23.

[11] 何 斌, 温远光, 刘世荣等. 英罗港不同红树植物群落土壤腐殖质组成及特性的研究. 土壤学报, 2006, 43 (3) :517-520.

[12] 杨继松, 于君宝, 刘景双等. 三江平原典型湿地土壤腐殖质的部面分布及其组成特征. 土壤通报, 2006, 37 (5) $: 865-868$.

[13］武春媛,李芳柏,周顺桂. 腐殖质呼吸作用及其生态学意义. 生态学报,2009,29(3) : 1535-1542.

[14] 郭亚新, 宋春雷, 刘云兵等. 长江中下游潜水湖泊沉积物多酚氧化酶与过氧化物酶活性分布. 水生生物学报, 2008, $32(3): 345-353$.

[15] 王毛兰, 胡春华, 周文斌. 丰水期鄱阳湖氮磷含量变化及来源分析. 长江流域资源与环境, 2008,17(1):138-142.

[16] 刘 妍,张建明,陈 政等. 洞庭湖水质污染现状及影响因素分析. 内陆水产,2007,(8):34-35.

[17] Wang Shengrui, Jin Xiangcan, Pang Yan et al. Phosphorus fractions and phosphate sorption characteristics in relation to the sediment compositions of shallow lakes in the middle and lower reaches of Yangtze River region, China. Journal of 
Colloid and Interface Science, 2005,289 :339-346.

[18］金相灿,刘鸿亮,屠清瑛等. 中国湖泊富营养化.北京:中国环境科学出版社,1990:121-133.

[19］中国科学院南京土壤研究所.土壤理化分析.上海:上海科学技术出版社,1978:121-134.

[20] Ruban JV, Lopez-Sanehez PF, Pardo G et al. Quevauviller harmonized protocol and certified reference material for the determination of extractable contents of phosphorus in freshwater sediments: a synthesis of recent works. Fresenius Journal of Analytical Chemistry, 2001, 370:224-228.

[21] 傅积平. 土壤结合态腐殖质分组研究.土壤通报,1983,14(2):36-37.

[22] 刘鸿亮,金相灿,荆一风. 湖泊底泥环境疏浚工程技术. 中国工程科学, 1999,1(1) :81-84.

[23] Kaiserli A, Voutsa D, Samara C et al. Phosphorus fractionation in lake sediments-Lakes Volvi Koronia, N. Greece. Chemosphere, $2002, \mathbf{4 6}: 1147-1155$.

[24] 范成新, 张 路, 秦伯强等. 太湖沉积物-水界面生源要素迁移机制及定量化-1. 铵态氮释放速率的空间差异及 源-汇通量. 湖泊科学, 2004,16(1):10-20.

[25] 何华春, 丁海燕, 张振克等. 淮河中下游洪泽湖湖泊沉积物粒度特征及其沉积环境意义. 地理科学, 2005,25 ( 5 ) : 590-596.

[26] 林心雄. 中国土壤有机质状况及其管理. 见: 沈善敏编. 中国土壤肥力. 北京: 中国农业出版社, 1998:111-159.

[27] Kipton H, Powell J, Fenton E. Size fractionation of humic substances: Effect protonation and metal binding properties. Analytica Chimica Acta, 1996,334:27-28.

[28] Koivula N, Hänninen K. Concentrations of monosaccharides in humic substances in the early stages of humification. Chemosphere, $2001, \mathbf{4 4}: 271-279$.

[29] 孙莉英, 倪晋仁, 孙卫玲. 不同粒径黄河沉积物中可提取腐殖质的含量分布及光谱特性. 环境科学, 2007,28(6): 1324-1331.

[30］平立凤,窦 森,张晋京等. 草原及开垦后土壤有机质性质研究. 应用生态学报,2004,15(5):824-826.

[31] 刘育红,裴海昆. 高寒草甸植被土壤腐殖质组成及性质研究.土壤通报,2004,35(5):562-565.

[32] 窦 森,姜 岩.土壤施用有机物料后重组有机质变化规律探讨. 土壤学报, 1988,25(3):252-261.

[33] Xu Jianming, Yuan Keneng. Dissolution and fraction of calcium-bound and iron- and alumimun -bound humus in soil. Pedosphere, 1993,3 ( 1 ) : 75-80.

[34] Elliott ET, Cambardella CA. Physical separation of soil organic matter. Agriculture, Ecosystems and Environment, 1991, $34: 407-419$.

[35] 魏自明,赵 越, 周连仁. 有机物料培肥对风砂土结合态腐殖质的影响. 农业系统科学与综合研究, 2004, 20 (2) : 143-148.

[36] 刘小虎,贾庆宇, 安婷婷等. 不同施肥处理对棕壤腐殖酸组成和性质的影响. 土壤通报,2005,36(3):328-333.

[37] 毛海芳.乌梁素-岱海有机碳的地球化学特征 [学位论文]. 呼和浩特: 内蒙古农业大学,2009.

[38] Schnitzer M, Ghosh K. Some recent advances in the chemistry and reactions of humic substances. J Indian Chem Soc, $1979,56: 1090-1093$.

[39] Dennis W, Oscarson, Rogers JS et al. The nature of selected prairie lake and stream sediments. Int Reme Ges Hydrobiol, $1981,66: 95-100$.

[40] 蔡 颖, 钟 巍, 薛积彬等. 干旱区湖泊沉积物腐殖化度的古气候指示意义一一以新疆巴里坤湖为例. 湖泊科学, 2009,21 ( 1 ) :69-76. 